\title{
4
}

\section{Theories of public organizations, design-projects, and professional activities: a Public Management Gallery tour}

If you were to sign up to a course with the theme of design-oriented public management, you would correctly expect to work on projects. In compensation, you'd hope for a short reading list. In this respect, you might be in for a surprise.

Glancing through the reading list, you see a blur of titles. Creating Public Value; Preparing for the Future; Strategic Planning for Public and Non-Profit Organizations; The Science of Design: Creating the Artificial; Problem-Solving in Organizations; Schemas in Problem-Solving; The Nature of Design; Why?, The Presentation of Self in Everyday Life; and those are just the starred readings. It doesn't help that most of the authors' names are unfamiliar: Moore, Bryson, Simon, van Aken and Berends, Barzelay and Campbell, Marshall, Cross, Tilly, and Goffman. Why so many readings, many not specific to public management? How is this going to work? Is it too late to shop for another course?

Why so many readings? There are two reasons. One is to demonstrate that public management is a discipline, with authors and readings that everyone who's educated in it should know. The other - more important - reason is that design-oriented professional practice is both a creativity-dependent and thinking-intensive phenomenon. Research on designing, and on inventive problem-solving generally, is clear that creativity involves generative, critical thinking about the purposeful phenomena with which professional practice is concerned. In a professional discipline, generative, critical thinking is developed through successive encounters with theories (and other forms of ideas) about such purposeful phenomena. If you're taking a course on design-oriented public management, you're going to encounter such theories. And as there are multiple purposeful phenomena in public management, your reading list will be longer than you might hope.

Why are many readings not relevant exclusively to public management as a professional practice? The reason is that there's a lot to this professional practice that is no less relevant to other areas of professional practice. What purposeful phenomena are specific to public management? Public organizations. What 
purposeful phenomena are common to public management and other areas of professional practice? One answer is problem-solving and design-projects. A further answer is professional activities, including sense-making, designing, argumentation, and dramatization.

The reading list for a design-oriented public management course is challenging not only because of its substantial size. The challenge is heightened because it's taxing to read literature from multiple fields, such as public management, management, problem-solving, cognitive science, designing, and social theory. Each has its own specialized vocabulary about the phenomena it focuses on and there is more than one way to theorize purposeful phenomena in the first place. And, as if that's not enough, studying these ideas is not just a matter of learning them: it's a matter of examining them critically, with a view to how they could be creatively used within professional practice - including those projects that you'll also spend time on in your course. Getting through the reading list is an even bigger ask than it may seem at first.

How is this going to work? This chapter addresses that all-important question. Before I explain how, let me tell you a story. A few years ago, as the academic year was about to begin, I ran into a colleague of mine in the main lobby of our building, as we waited for the lift. Professor Chrisanthi Avergou was just back from sabbatical; and, intriguingly, she was looking forward to returning to teach her core course on the information systems master's degree. She told me, to my surprise, that she had used some of her sabbatical to write and record videos about some of the extensive theoretical material in her course, and she was hoping that viewing the videos would help students engage with that material, also saving time for critical discussion of it during class.

Eventually I followed suit in my own course on public management by scripting and recording lecture material about some work of Herbert Simon and Mark Moore, among others. I intended for this material to be used both inside and outside my LSE courses. However, it took me a while to come up with the concept for the collection of videos that I planned to do. What finally came to mind was that our field needed an anthology of classic writings. But I feared that the terminology of an anthology of readings would spoil the (admittedly inflated) idea that the videos were a cutting-edge innovation. So, I needed to work on the concept.

Several years earlier, during a getaway weekend in Berlin, I had visited the Bauhaus Archives, a museum about the celebrated Bauhaus School, which existed in Germany from 1929 to 1933 . As is well-known, Bauhaus is considered a primary source of the very idea of "design" - an idea that encompassed architecture, industrial product design, graphic design, and fashion design. ${ }^{1}$ The School's leadership and faculty included the most prominent architects and artists of the time in central Europe, including Walter Gropius, Johannes Itten, Wassily Kandinsky, Paul Klee, László Moholy-Nagy, Hannes Meyer, and Ludwig Mies van der Rohe. As for the Bauhaus Archives, the museum exhibition mainly consisted in displays about these individuals, their work, their positions in relation to contentious issues within and outside the School, and their ideas about designing and education for it. What brought all of this information to life was 
the audio-guide, which was exceptionally well-scripted and pleasantly spoken. The whole visit to the Bauhaus Archives made a big impression on me.

It was about a year later that I started to script and record videos about public management authors and their works. The first video I made was about Herbert Simon and his reputation-making 1946 article on "The proverbs of administration." I introduced Simon, identified the issues that he raised in this piece, stated his claims, and presented his argument. I went on to critique the piece as well - arguing that he broke some rules of proper argumentation. After I released the video, I remember explaining to a colleague that it was sort of like a segment of the audio-guide I had listened to while visiting the Bauhaus Archive. Some months later, I built on that idea. I decided that public management needed something like a Bauhaus archive museum, and that a collection of my videos could serve as a virtual one. So, I conjured up the idea that I was creating a Public Management Gallery, consisting of a collection of related displays and audio guide segments about our field's leading lights, past and contemporary. The entire suite of videos would be called the Public Management Gallery Tour. I had my concept, and a narrative line about it.

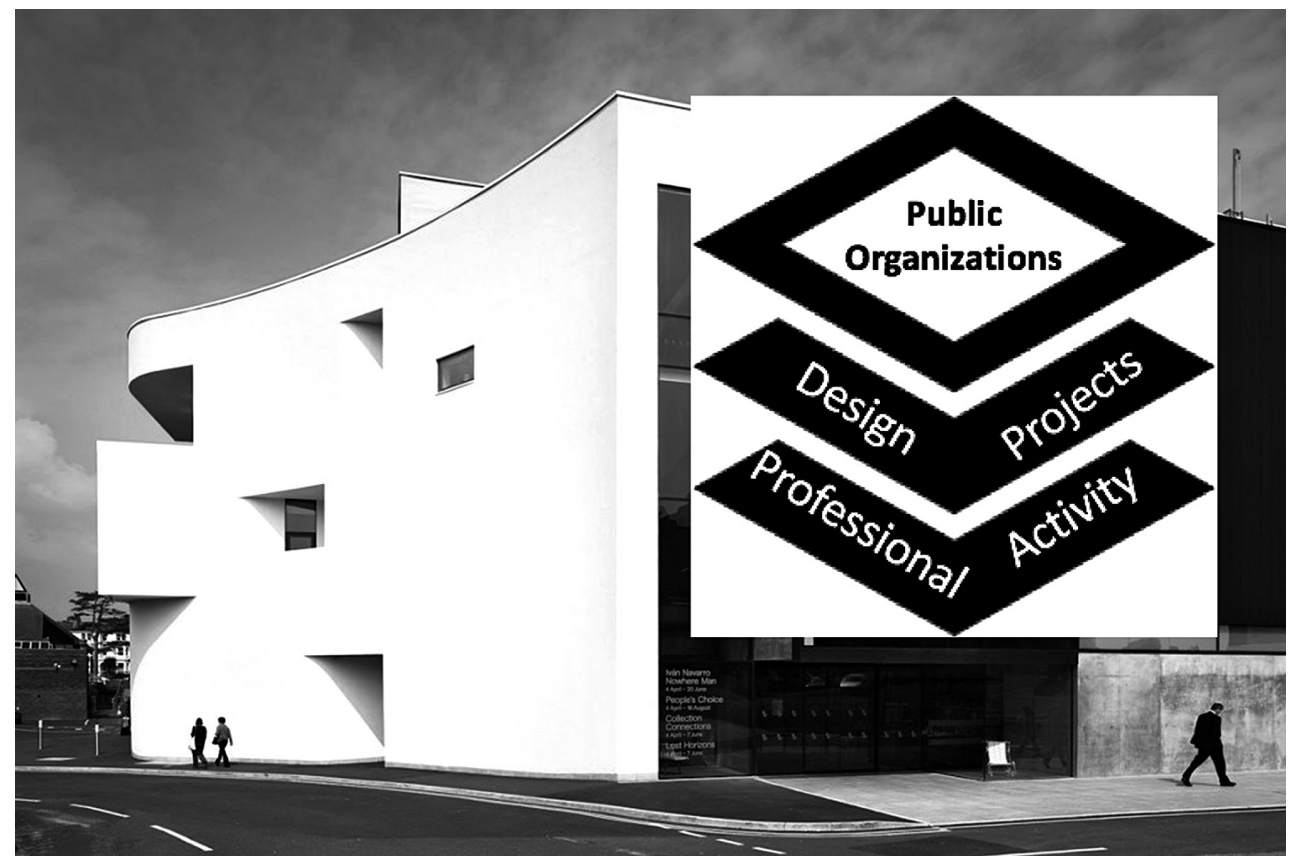

Figure 4.1 The Public Management Gallery

This chapter is a visit to the fictional Public Management Gallery. The Gallery is divided into three floors, with each floor exhibiting theorizing about the purposeful phenomena involved in public management practice: public organizations, design-projects, and professional activities, respectively. Each floor of the Gallery consists in a few displays, each about the purposive theorizing in one 
publication. Each display is accompanied by an audio-guide presentation about that publication.

In relation to the teaching-and-learning enterprise within the professional discipline of public management, this chapter's specific role is to introduce you to the purposeful, mechanism-intent phenomena with which public management is concerned and, more specifically, to how they have been theorized. These purposive theories are meant to be critically examined, as part of the teaching-andlearning enterprise. They are also meant to be used in channeling a generative, critical-thinking process in an educational setting. Let the show begin.

\section{Entering the Public Management Gallery space and meeting the curator}

You and a companion have made your way to the Public Management Gallery, walking to the entrance on the upper level. You continue into the exhibition's anteroom. On one wall is a word cloud image.

You settle your earbud headphones into place and touch the audio guide's icon for the play command. What you hear is as follows.

Welcome to the Public Management Gallery and to this audio-guide for your self-guided tour. My name is Michael Barzelay. While you're visiting the Public Management Gallery, I'll be your host. Let me briefly introduce myself. I'm from the USA. I consider my home to be Connecticut, although I haven't lived there during the past 35 years. I've been involved academically with

Figure 4.2 The Public Management Gallery word cloud

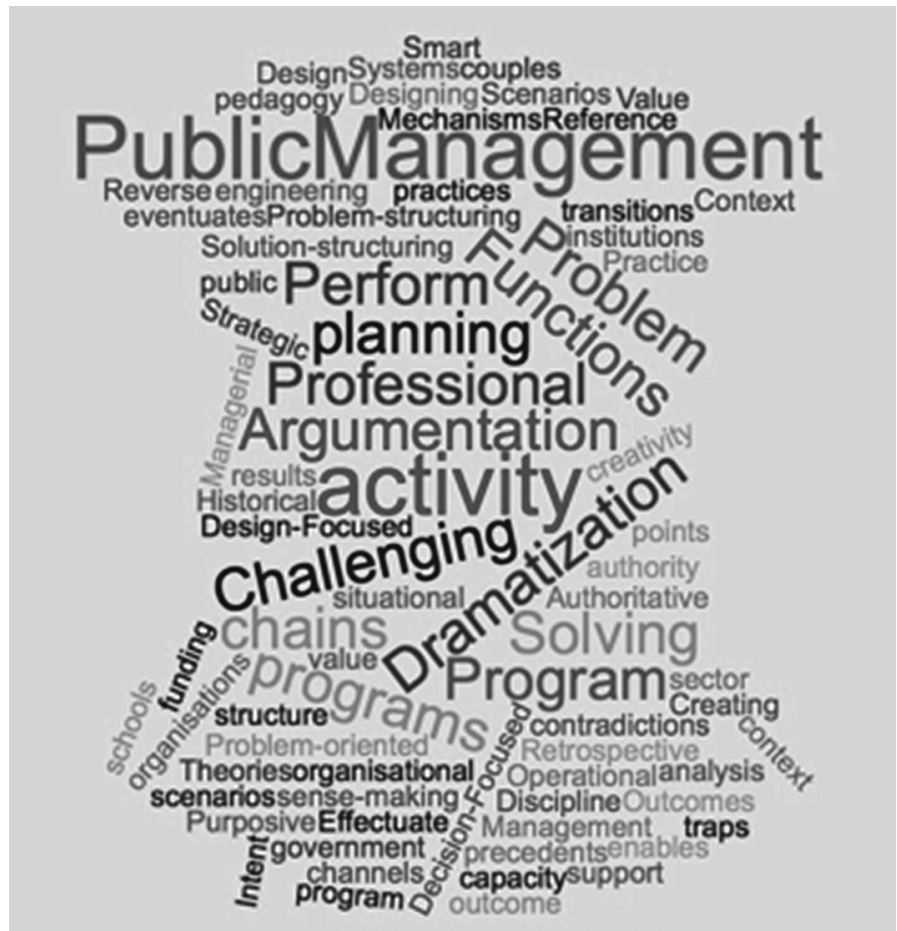


public management since 1980. At the time I was a student on Yale's public and private management master's degree, in its School of Management. When I did my $\mathrm{PhD}$ in political science, I didn't have anything to do with public management. I took my qualifying exams in contemporary analytic political theory, international relations, and comparative West European politics. My dissertation was a case study about sector-specific policy-making in politicized market economies; my supervisor was Charles E. Lindblom. In 1985, after finishing my $\mathrm{PhD}$, I became an assistant professor at Harvard's Kennedy School of Government; part of the deal was that I was going to teach public management, which I did, for ten years. I moved to London School of Economics and Political Science (LSE) after that long period. I've taught public management to students on degrees all across the LSE. I've also practiced public management in a way, when I headed LSE's Department of Management for a few years. I've been the co-editor of the academic journal, Governance. I've done a lot of consulting and I collaborate with a government-based school of public administration in Latin America. That's me.

My role in the Public Management Gallery is as the founding curator. I founded the Gallery to pursue my passion of fostering a reality where public management is a design-oriented professional discipline. There's a lot packed into this statement, more than I can discuss in this audio guide. If you're really interested, read my book, Public Management as a Design-Oriented Professional Discipline, which is in stock at the Gallery bookstore.

The exhibition is laid out on three floors. Each floor's gallery space will feature authors and the purposive theories that they presented in their publications. Each floor is themed. The upper floor, where you are standing now, is about purposive theorizing of public organizations. The mezzanine floor, just below, is centered on design-projects. The lower floor is centered on the professional activities of sense-making, designing, argumentation, and dramatization. Now, if you will, please proceed into the Gallery proper and focus your attention on the first display area.

You now leave the Gallery's anteroom, turn a corner and enter the Public Organizations exhibition. The first exhibition room is bright and airy, thanks to being on the upper floor. Off to the left, a clutch of people is seated on cushioned benches, listening to the Gallery Tour audio guide on their own smartphones.

You spot an empty space on the front bench, move expeditiously toward it, excuse yourself to your soon-to-be-neighbors, sit down, and advance the audio guide to the next recording segment. Without a wait, the curator's voice is heard again.

\section{Listening to purposive theories of public organizations: Moore's Creating Public Value}

This exhibition room is devoted to one of the most well-known academic theorists of the professional practice of public management - Mark Moore. He has been a professor at Harvard University for his entire academic career, mainly 
based in the Kennedy School of Government. For quite a stretch of time - something like 15 years - Moore was effectively in charge of public management teaching within that school. He chaired and taught in executive programs, shaped the master's curriculum, sponsored the writing of dozens of teaching case studies, influenced faculty hiring (including my own appointment there), and wrote a book about public management, entitled Creating Public Value: Strategic Management in Government. The book took almost 15 years to write, and it was published in 1995 by Harvard University Press. ${ }^{2}$ It was presented as being emblematic of the Kennedy School's approach to public management, and that was how it has largely been read. It "stands for" an approach to public management, just as much as it advances particular lines of argument.

It would be uncharitable to suggest that this book is best known for its title. But there's enough truth in this statement to make the title a point of entry into a discussion of the book. The first thing you'll notice about the title is that it has two parts. Typically, you can't reverse the order of a book's main title and subtitle and have it make just as much sense. Moore's book is definitely atypical in this way, among many others.

To understand the relation between the two parts of the title, you need a little background. Specifically, you need to know about the sources of the ideas of "creating value" and "strategic management," referenced in the main title and sub-title, respectively. The proximate source was Harvard Business School. The proximity was partly geographic: if you look on Google Maps, you'll find the distance between those schools is 750 meters (or a half-mile in local terms), thanks to there being a bridge across the Charles River. There was also an institutional connection: some professors at Harvard Business School (HBS) had been involved in curriculum development and teaching about public management during the late 1970s and early 1980s, as was Moore, when he was still a youthful faculty member. In crossing The River, the business school professors brought along the HBS case method pedagogy, as well as the idea of strategic management. The idea of "creating value" was also part of the HBS lexicon, though that idea gained much greater currency as the 1980s progressed, for a raft of reasons, including the growing prominence of Michael Porter and his approach to business strategy. ${ }^{3}$

To understand the idea of strategic management in government, you need to know about the precedent idea of strategic management in big companies. ${ }^{4}$ The roots of this idea can be found in a most famous theorization of enterprises and their management, which was published around the time of World War I, by Henri Fayol..$^{5}$ In its English translation, it was titled General and Industrial Management. Fayol's theory was about enterprises, a kind of purposeful phenomenon. It wasn't about organizations as a kind of empirical phenomenon; and it wasn't about specific enterprises. It was a purposive theory of commercial enterprises as a type.

Fayol's theory had some of the same form as systems or functional biology, invented by Aristotle. ${ }^{6}$ Fayol theorized enterprises as being functionally invariant, just as is the case for biological theories of human organisms; our bodies are uniform in performing such functions as respiration and circulation, for example. Under Fayol's purposive theory of enterprises, these phenomena are 


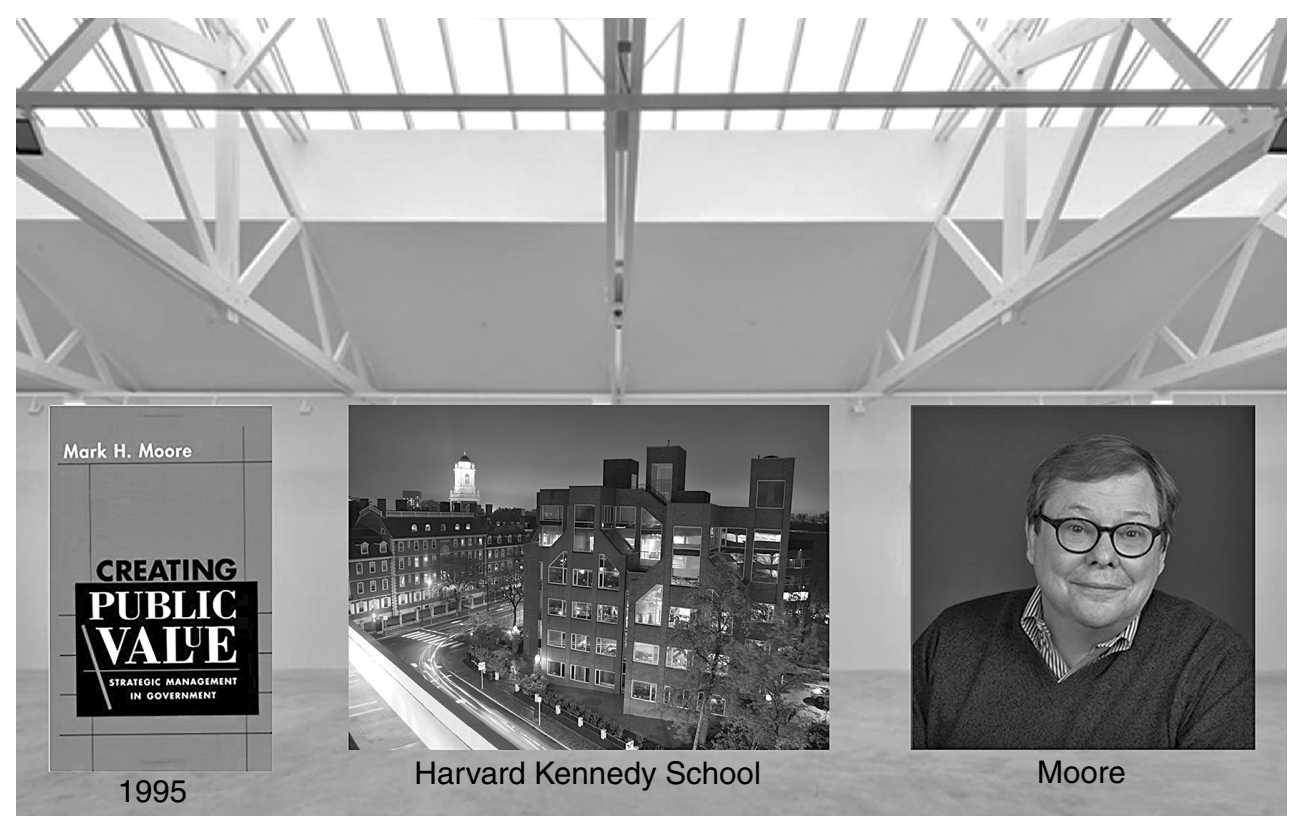

Source: Creating Public Value: Strategic Management in Government by Mark H. Moore, Cambridge, MA: Harvard University Press, @ 1995 by the President and Fellows of Harvard College. (Book jacket image reprinted with permission.)

Figure 4.3 The Public Management Gallery display on Mark Moore and Creating Public Value

uniform in that enterprises can't survive or thrive without performing six functions: in alphabetical order, these functions are accounting, commercial, finance, management, security, and technical. Without performing the technical function, an enterprise wouldn't be able to offer products for sale. Without performing the commercial function, an enterprise wouldn't sell its products. Without performing the security function, an enterprise would lose control of what it owns. Without management, the enterprise would lack organization, direction, and coordination. Fayol went on to discuss the management function in detail; how it enables the other enterprise-functions; and, most of all, how it can be performed by the activities of professional practitioners working in directive roles in commercial business organizations.

In form, "strategic management" is basically the same as Fayol's theory of enterprises. It's a purposive theory. Enterprises are the purposeful phenomenon. Performing enterprise functions is necessary to effectuate enterprise-intent. Management is an enterprise-function that enables all other enterprisefunctions to be performed. The most important aspects of the management function are performed through the activities of executives, particularly those holding positions located within an organization's "strategic apex."7 By the early 1960s, other layers of argument had been added to Fayol's purposive theory of enterprises to form "strategic management." These layers included developments in the field of management (such as the work of Chester Barnard ${ }^{8}$ ) and in the social scientific study of decision-making in organizations (such as the 
work of Herbert Simon and James G. March ${ }^{9}$ ). But the form didn't substantially change.

Let's use this historical account to get a feel for Creating Public Value: Strategic Management in Government. Both Fayol's enterprises and Moore's public organizations are theorized as effectuating enterprise-intent. In Moore's book, the substance of enterprise-intent is labeled as public value. The content of this idea draws on political theory. Moore holds that public value consists in the realization of political aspirations for aggregate social conditions. He also holds that the restriction of liberty through the exercise of public authority cuts in the opposite direction.

While the argument about the substance of enterprise-intent draws on political theory, the argument about the effectuation of enterprise-intent draws on legal and empirical theorizing about state authority and institutions. A feature of this line of argumentation is that the use of public authority requires legitimacy, while the use of public money requires political support. Another feature of this argument about the effectuation of enterprise-intent is that program delivery the analogue to the technical function in Fayol's theory - needs to be performed.

Moore brings these lines of discussion together, to answer the question of what's required for a public organization to effectuate public value, in Chapter 3 , where he presents the idea of a "strategic triangle." Its corners represent the ideas of value, legitimacy and support, and operational capacity. Value refers to the substance of public value. The related ideas of legitimacy and support have already been mentioned. Operational capacity is what is required to deliver programs. Thus, public value is effectuated by (a) performing the program delivery function and (b) the legitimacy and support of the public organization and/or program.

Moore's theory of professional practice by public managers hangs off his purposive theory of public organizations. A public manager should think deeply about enterprise-intent, in public value terms, and a public manager should think and act imaginatively and deliberatively about how public value is to be effectuated. When doing that, the contributing factors of operational capacity, on the one hand, and legitimacy and support on the other, deserve utmost attention. That is the overarching idea of strategic management in government, in a nutshell.

Moore works out implications of these ideas for the professional practice of public managers, in the form of guidelines and frameworks. For example, Moore provides guidelines for dramatizing a public organization: the guidelines involve the presentation of an organization's mission. As another example, Moore lays out multiple, contrasting profiles of a public manager's engagement with a public organization's authorizing environment; the profiles include bureaucratic entrepreneurship, policy development, and negotiation. In later chapters, where the focus is on innovation and operational capacity, Moore echoes Fayol's ideas about planning and controlling, two constitutive functions of management in his purposive theory of enterprises.

All that said, many of the implications take the form of case commentaries. That's a hallmark of a Harvard tradition of management theorizing; it has an 
important history of its own, in law school education and in a form of moral theorizing called casuistry.

Moore's book makes good reading. The first chapter is about a Town Librarian who thinks imaginatively and deliberatively about how to effectuate public value, taking into account an observed shift in patterns in library usage, especially during the after-school hours. Chapter 3 presents the strategic triangle and the guidelines about dramatizing a public organization through the formulation of statements of its mission. And, if you want to know more about Moore's book, and its relation to management theory, then have a look at Chapter 2 of my book, Public Management as a Design-Oriented Professional Discipline.

I would now invite you to move forward to visit the second display on this level of the Public Management Gallery. It's about another purposive theory of public organization, and it features another famous professor of public management. I hope you can find a spot on the bench in front of that display, as I have a lot to say about it.

\section{Listening to purposive theories of public organizations: Bryson's Strategic Planning for Public and Nonprofit Organizations}

The professor featured here is John Bryson. If you're involved with the field of public management as an academic, then you're sure to be very familiar with Bryson's ample and influential scholarship. If you're involved with public management as a professional practitioner, you're very likely to have come across -

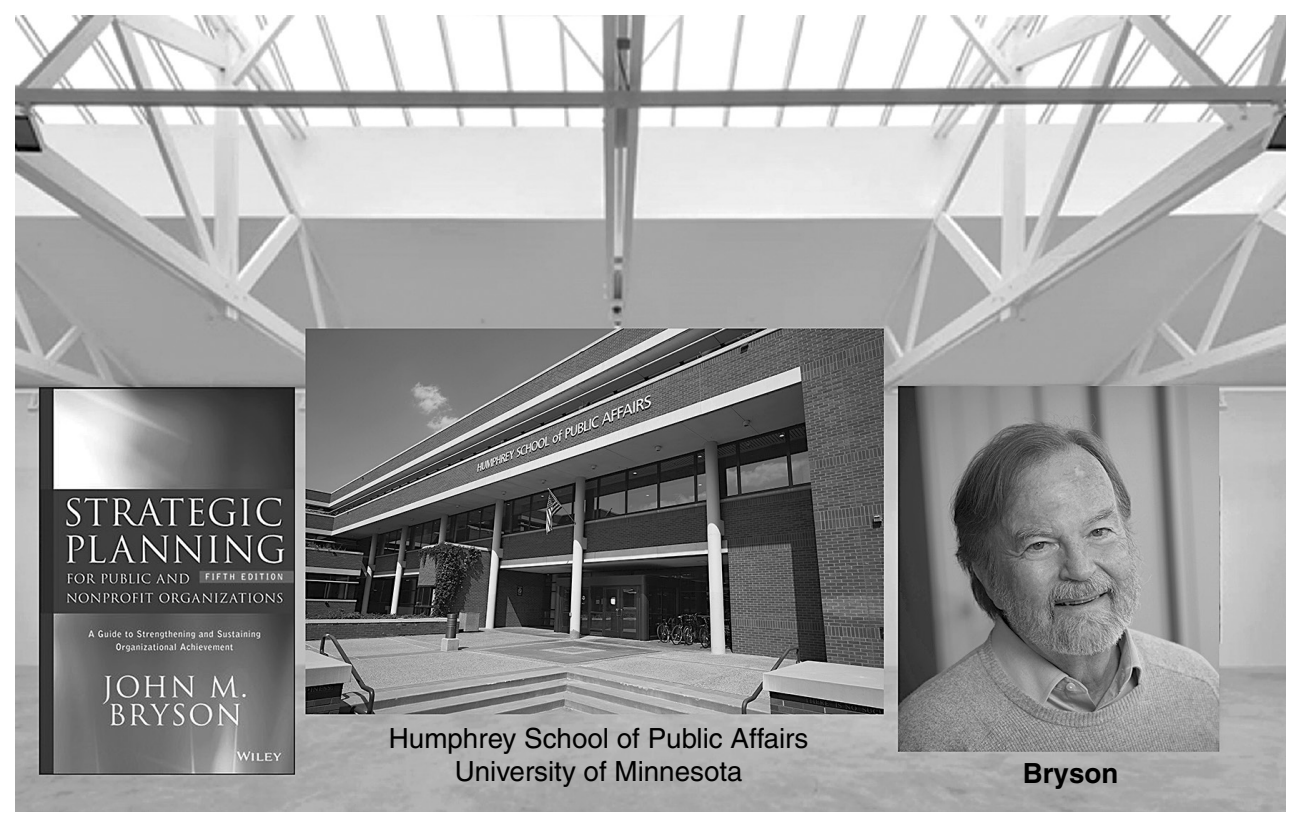

Source: Strategic Planning for Public and Nonprofit Organizations, by John M. Bryson, @ 2018 by John Wiley \& Sons. (Book jacket image reprinted with permission.)

Figure 4.4 The Public Management Gallery display on John Bryson and Strategic Planning 
and even used - one or more of the five editions of Bryson's major statement about strategic planning.

The main title of this book is Strategic Planning for Public and Nonprofit Organizations. The cover of the fifth and most recent edition - published in 2018 is featured in the display in front of you.

Bryson is McKnight Presidential Professor of Planning and Public Affairs at the University of Minnesota, based in the Hubert Humphrey School of Public Affairs. He has been on the Humphrey School faculty for decades, and twice serviced as Associate Dean. He is a prolific researcher and well-regarded (and liked!) academic leader in the field of public management.

The main title indicates that Bryson's book is a purposive theory of two different forms of enterprises: public organizations and nonprofit organizations. It focuses on strategic planning. So, let's start there. Bryson defines strategic planning as follows: "Strategic planning helps produce fundamental decisions and actions that shape and guide what the organization is, what it does, and why it does it."

Let's clarify what this statement means by asking what strategic planning is for, what it consists in, and how it works. Those are questions to ask about purposeful phenomena like strategic planning.

What strategic planning is for is indicated by the book's sub-title: strengthening and sustaining organizational achievement. That's Bryson's way of phrasing the idea of "effectuating enterprise-intent," language that I introduced in likening Moore's book to Fayol's purposive theory of enterprises. It may be worth pointing out that Bryson's preface mentions several terms that relate to the idea of organizational achievement: fulfilling missions, meeting mandates, satisfying constituents, and creating public value.

We can be a bit more specific about what strategic planning is for, if we liken Bryson's purposive theory of public organizations to Fayol's purposive theory of enterprises, with some depth. Remember that within Fayol's theory, enterprises can't survive or thrive without performing six functions: accounting, commercial, finance, management, security, and technical. Remember that without management, the enterprise would lack organization, direction, and coordination. Consider that without the management function being performed adequately, the other enterprise-functions will suffer, altogether undercutting the prospect of effectuating enterprise-intent.

Now recall that strategic planning, under Bryson's definition, "shapes and guides" the public organization. That phrasing suggests that the idea of "strategic planning" in Bryson's purposive theory of public organizations is closely related to the idea of "performing the management function" in Fayol's purposive theory of enterprises. This relationship between ideas can be stated more precisely. Strategic planning is for performing the enterprise-function of management in public organizations, which, in turn, enables the performance of other enterprisefunctions, which, in turn, strengthens and sustains the achievement of public organizations.

Let's sharpen up this idea by next answering the question of what strategic planning consists in. Recall that Bryson's definition states that "strategic planning 
helps produce fundamental decisions." That statement suggests that strategic planning is a decision-making process. Put in terms of mechanism-intent thinking and analysis of enterprises, strategic planning is a scenario-process within organizations, whose profile is that of decision-making. By definition, scenarioprocesses eventuate in outcomes. Thus, strategic planning eventuates in decisions about the enterprise.

More can be said about what strategic planning consists in. But before breaking this idea down further, let's consider the third question: how does strategic planning work? It's a more interesting and potentially fruitful question to examine, compared to the questions of what strategic planning is for, and what does it consist in.

You can't expect that you'll get a sharp answer to that question from a definitional statement. But there are hints in Bryson's definition of strategic planning, which, as you will recall is that: "Strategic planning helps produce fundamental decisions and actions that shape and guide what the organization is, what it does, and why it does it" (emphasis added). We've already established that strategic planning is for performing the management function; so the question is how it does that. How do decisions that eventuate from strategic planning shape the organization? The answer to this is that they give rise to "actions" that change how the public organization's enterprise-functions - such as the technical or security functions - are performed. Fine, but how do decisions that eventuate from strategic planning lead to such actions and their downstream effects? That's a question that Bryson's definition of strategic planning can't answer: but there's nevertheless a hint in the term "fundamental decisions." The hint is that strategic planning works when participants in the organization believe that the decisions eventuating from strategic planning truly address the enterprise's fundamental issues.

Let's summarize where we have been before adding more depth to this account of Bryson's purposive theory of strategic planning for public organizations. Strategic planning is for performing a public organization's management function, which means that it is for enabling the performance of all enterprisefunctions, which means it is for effectuating sustained organizational achievement. Strategic planning consists in scenario-processes within organizations, whose profile is that of decision-making. Strategic planning works by generating actions that change how enterprise-functions are performed.

There's much to be added to this summary. We have time for only one further step in this direction. In the preface to the fifth edition of his book, Bryson states that "strategic planning at its best makes extensive use of analysis and synthesis in deliberative settings to help leaders and managers successfully address the major challenges that their organization (or other entity) faces" (p. xvi). This statement implies that if strategic planning is to work, its scenario-processes need to include a phase that eventuates in a decision identifying the enterprise's major challenges. It also implies that the decision-making process has to be deliberative: a characteristic that - as a matter of sociological theory - grows out of its activity and its context.

There's a second implication of the idea that "strategic planning at its best 
makes extensive use of analysis and synthesis in deliberative settings." Analysis and synthesis are defining ideas in purposive theories of designing. In those theories, analysis enables synthesis, and synthesis eventuates in designs, that is, representations of objects. In the context of strategic planning, designed objects could be representations of "major challenges" as well as of "fundamental decisions."

We should thus revisit the earlier definition of strategic planning, within Bryson's purposive theory of public organizations. Nothing changes in what strategic planning is for. But something changes in what strategic planning consists in. It consists in scenario-processes with two distinct profiles: designing and decision-making. If strategic planning is different in what it consists in, then it has to be different in how it works. And it works by designing enabling decision-making. As Bryson stated: "Strategic planning at its best makes extensive use of analysis and synthesis in deliberative settings to help leaders and managers successfully address the major challenges that their organization (or other entity) faces." Please bear this thought in mind when you go down to the Mezzanine level of the Gallery, which is about design-projects.

Bryson's book includes a wealth of frameworks and guidelines that elaborate this purposive theory of strategic planning and public organizations. The master guideline for strategic planning is the following 10-step approach:

1. Initiate and agree on a strategic planning process

2. Identify organizational mandates

3. Clarify organizational missions and values

4. Assess the external and internal environments to identify strengths, weaknesses, opportunities, and threats

5. Identify strategic issues facing the organization

6. Formulate strategies to manage the issues

7. Review and adopt the strategic plan or plans

8. Establish an effective organizational vision

9. Develop an effective implementation process

10. Reassess strategies and the strategic planning process.

The chapters in Bryson's book are organized around this master guideline. Each chapter provides specificity around how to perform a given step. In each case, the scenario-process is more detailed, in terms of its outcome, its activity, and in the tools that can be used to help produce the outcome. It's a very well structured and detailed purposive theory, making it quite useful.

This is probably as good a point as any to bring this audio-guide presentation on John Bryson and his strategic planning book to a close. You should now be able to tackle the task of reading and appreciating it as a purposive theory of strategic planning and public organizations. Besides that, you will now be able to compare, contrast, and integrate this purposive theory with Moore's. That will be good for your professional knowledge about public management, and it will be good for the professional discipline of public management. It's something you might do if you're taking a course on public management. 
Before you head down to the mezzanine level for the continuation of the Gallery Tour, why don't you visit the café around the corner to the right. You can also re-charge your smartphone for the next leg of the Gallery Tour.

\section{Listening to purposive theories of design-projects: Herbert Simon's The Sciences of the Artificial}

Welcome to the Mezzanine Level of the Public Management Gallery. As you enter, take in a sweeping view of the three displays on design-projects that you will be viewing here:

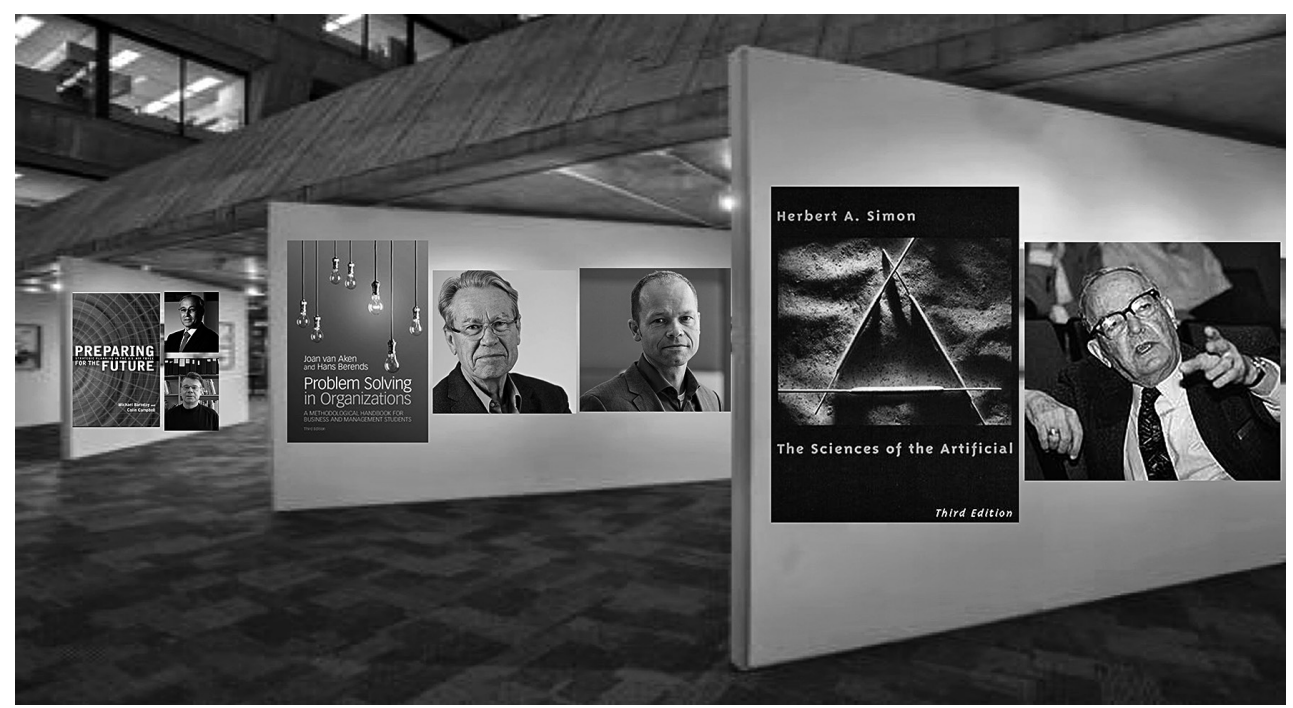

Source: Simon, Herbert, The Sciences of the Artificial, third edition, [Cover], () 1996 Massachusetts Institute of Technology, published by the MIT Press. (Book jacket image reprinted with permission.)

Figure 4.5 Entering the exhibition section on design-projects

I'll be giving you a brief account of each one in this series of audio-guide segments. Together, they should give you a sense of the important role played by the idea of design-projects in purposive theorizing about public organizations and the professional practice of public management.

We begin with Herbert A. Simon and his book, Sciences of the Artificial. ${ }^{10}$ There's a ton that you really ought to know about both. I will tell you as much as I can within the short period during which you will be comfortable standing in front of the display.

It's almost impossible to imagine that anyone who takes the time to visit the Public Management Gallery wouldn't recognize the name, Herbert A. Simon. Let me give you a test to see how much you already know. Here are some questions: state whether you think they are True or False.

First, Herbert Simon was awarded the Nobel Prize in Economic Sciences in 1978. True or False? True, you say? You are CORRECT! 
Second, Herbert Simon was an economist. True or False? True, you say? WRONG! His PhD was in Political Science. For a while he taught in a business school. He was a professor of computer science and psychology. He was a lot of things, but an economist wasn't one of them.

Third, Simon was an organization scientist. True or False? True, you say? CORRECT! He devoted quite a lot of his work to understanding what favored and disfavored the making of intelligent decisions within organizations. And surely that work was theoretical in character. Not only did the work claim to be true of organizations generally and universally, but it also drew on theoretical ideas, from many sources, including philosophy and psychology.

Fourth, Simon proposed that the discipline of management be developed as a design science rather than as a professional practice. True or False? False, you say? CORRECT! Simon proposed that the discipline of management be developed as a professional practice, and that this should be done through rational inquiry about solving problems through the complementary activities of designing and decision-making, especially within organizational settings. Simon came up with the sticky label of "a science of design" to refer to such rational inquiry, which he hoped would play a role in the teaching and learning enterprise of the professional discipline of management, among others. But he didn't say that management itself should be a design science. Others have said Simon advocated that management become a design science, but that doesn't make it true.

Now, tally up your score. Of your four responses, three were correct. Overall, your responses show that you're quite well informed about Herbert Simon. And it's unlikely that your beliefs will go out of date, because Simon isn't with us any longer. Sure, you didn't get a perfect score. But the incorrect response was probably due to being primed to thinking that somebody who won the Nobel Prize in Economic Science was an economist. No worries: this just shows that your brain processes information like everyone else here in the Public Management Gallery. You can feel at home.

Let me remind you why Simon is here with us in the Public Management Gallery. Remember this image, from when you entered the building?

Well, you're now on the mezzanine floor. That suggests that Simon is here because he had something to say about design-projects. And so, let me now tell you why THAT is true and what you might want to remember about the relationship between design projects, on the one hand, and public organizations and professional activity, on the other.

Simon had something to say about design-projects in his book, Sciences of the Artificial, the third and final edition of which is pictured in the display. Where, specifically? Try the index. If you look through the index for "projects," you won't find any entry. So, try the entry for "design," then look for "projects" as a sub-entry. Find the sub-entries that begin with P. You find "problems, largescale." And then "process of." Getting closer to "projects." But the next sub-entry is "representation of." It begins with R. So, perhaps the association between Simon and "design-projects" is just something in your curator's mind?

While I have encoded the term "design-projects" in the Public Management 
Gallery Tour, I dare you to deny that this idea was central in the chapter of Sciences of the Artificial, entitled "The science of design: creating the artificial." In that chapter, Simon analyzes a scenario-process that eventuates in decisions that lead to - and structure - an artificial system's realization. All of the constitutive activities of the scenario-process are located within the same span of time. Some of the constitutive activities eventuate in more than one representation of an artificial system's design. Such designs channel other constitutive activities that eventuate in decisions. These two categories of activities - designing and decision-making - cease at some point, as when the organization is satisfied with the artificial system concerned and with the decisions made about it, or possibly for other reasons. This scenario-process is the concept that I label "design-projects." To invoke an old-fashioned American idiomatic expression, "if it looks like a duck and sounds like a duck, then it's a duck."

There are a couple of more substantive reasons why I feel confident about using this label. One is historical. A fairly recent book about the history of business schools in North America provided some detail about Simon's work and what influenced him. ${ }^{11}$ To make a complex story simple, Simon's real-world analogue to the scenario-process just presented was projects he participated in, as an affiliate of RAND Corporation; and the mother of historical precedents for those projects was, in turn, the Manhattan Project, which eventuated in an artificial system for prosecuting World War II with U.S.-controlled atomic weapons. Augier and March also explain how Simon came to see "problemsolving" through collective generative and deliberative processes as being an essential form of organizational activity in business and other forms of enterprise. Accordingly, as a matter of history, Simon saw design-projects as being a universally key mechanism for effectuating enterprise intent - whatever words he used to communicate this view.

The other substantive reason is that the notion of design-projects provides a direction for purposive theorizing of public organizations and the professional practice of public management. It's a direction that is missing from mainstream theorizing of enterprises. As a matter of history, design-projects were not part of Fayol's purposive theorizing of an enterprise's management function, though, as an aside, he probably did think of projects as being mechanisms for an enterprise's technical function. The idea of design-projects is also marginal to purposive theorizing about public management. Specifically, the terminology of design-projects is missing from Moore's book: if you look in the index for either "design" or "projects," you'll come away without a reference. It's even marginal to the vocabulary of Bryson's book. There's no index entry for projects; and the most related sub-entry for strategic planning is "process." That suggests that even Bryson's purposive theorizing of public organizations didn't take full advantage of Simon's suggested direction for theorizing management. So, I state my case: design-projects have a major role to play in purposive theorizing of public organizations and public management; and time will tell if this direction for theorizing comes to pass, and how well it works.

If you'd like to know more about Simon's theorizing about design-projects, you have three options. One is to read Chapter 5 of Sciences of the Artificial. 
A second is to read Chapter 2 of my book, Public Management as a DesignOriented Professional Discipline. A third - the best option - is to read both.

\section{Listening to purposive theories of design-projects: Problem-Solving in Organizations}

This segment of the Gallery Tour is principally about Professor Joan van Aken, on the one hand, and the book, Problem-Solving in Organizations, on the other. On the display, you can see the book jacket of the third edition of this book, which I will refer to, for the sake of brevity, as PSO. Published by Cambridge University Press, PSO is co-authored by van Aken and Hans Berends, ${ }^{12}$ whose handsome images are staring back at you from the display.

If I'm right, you're likely expecting me to explain why you've encountered van Aken and Problem-Solving in Organizations, spot in the middle of the Public Management Gallery Tour. Let me tell you a story.

I came across the first edition of PSO as a result of studying van Aken's articles that advanced the idea that management should be researched and taught as a design science. ${ }^{13}$ I was impressed with what I read - and checked him out. I got hold of PSO. I discovered that the book was written not only as a synthesis of theorizing about problem-solving in organizations, but also as a guidebook for students on undergraduate business courses who have to complete a business project in their final year of study. It was written clearly and succinctly. I felt that my own students might like to read a number of the chapters. Besides that, I had been looking for a reading that would introduce my students to ideas about designing - one that wouldn't be about designing machines, products, and/or software. PSO ticked that box; indeed, it brought in ideas about designing in order to add some depth to ideas about problem-solving in organizations, which had otherwise tended to be indistinguishable from literature on decisionmaking. So, I assigned two of the early chapters of PSO for the second week of my course.

I was in for a surprise. My students didn't like PSO; they loved it. A week later, one student told me he used the material during a team exercise within a recruitment event for a consulting company. He was able to get the other team members to follow his lead. (Eventually he got the job, and LinkedIn tells me he's working for McKinsey.) I kept using the material, year after year. I have recommended it to other teachers, and everybody likes it (at least).

As I wrote my book, Public Management as a Design-Oriented Professional Discipline, I came up with the idea of a three-layered pattern of purposive theorizing and professional knowledge about public management, with the middle-layer being about design-projects, sandwiched between a layer above, for purposive theorizing about public organizations, and a layer below, for theorizing about professional activity. If the middle layer was going to be about design-projects, I needed material to represent purposive theorizing about them. That's the story.

Now the argument: The reason PSO has a place in the Gallery Tour is that it spells out a purposive theory of design-projects in a fuller way than Simon did. Indeed, PSO translates Simon's ideas into a theory of design projects and into 
a purposive theory of enterprises, while picking up on some of the history of thought of problem-solving.

Some of the early theorizations of problem-solving were formulated between the two world wars of the twentieth century, as part of an intellectual movement known as pragmatism. A major figure in this movement was John Dewey; his most famous statement about problem-solving was The Public and its Problems. Dewey's theorization of problem-solving was enormously influential, and it was elaborated by many leading mid-twentieth-century thinkers in sociology, law, political science, and economics at U.S. universities. The best known such thinkers include Herbert A. Simon, Harold Lasswell, ${ }^{14}$ Albert O. Hirschman, ${ }^{15}$ Charles E. Lindblom, ${ }^{16}$ James G. March, and Aaron Wildavsky. They didn't agree with each other on everything, but their writings certainly added great intellectual depth to debates about the constitution and possibilities of problem-solving.

Van Aken and Berends' book, while reflecting the history of debates about problem-solving, provides a distinctive line of argument about professional practice in organizations. In summary form, their argument is that business projects are mechanisms to perform enterprise functions, while this type of mechanism is constituted, essentially, by a line of design activities. This line of activity eventuates in well-formed precursors to solved problems, consisting in object and realization designs. These precursors structure and/or feed other scenario-processes consisting in decision-making activities. Decision-making activities eventuate in decisions about preserving, modifying, or replacing mechanisms for performing an enterprise's functions; in substance, such decisions may involve adopting and implementing the object and realization designs that eventuated from the earlier business project.

In line with this sketch, PSO taps into the idea - immanent in Simon's main line of theorizing in Sciences of the Artificial - that purposeful phenomena, or solutions, within enterprises are artificial systems. You can see this slant in the way van Aken and Berends label the process-outcomes of problem-solving scenarios, specifically, "object designs" and "realization designs." An "object design" specifies a purposeful phenomenon as it is to exist at a later point, once the downstream activity of realization makes the object design fully real - but an object design is silent on specifics of the realization activity. Conversely, a "realization design" is silent on the object specification, but does specify the downstream plan in enough detail that the object design can be realized.

As you'll intuit immediately, the vocabulary of object and realization design is anchored in engineering and architecture; fabrication is a standard term for realization in engineering, while construction is a standard term for realization in architecture. Given this vocabulary, it makes sense for van Aken and Berends to theorize business projects as a cascade of activities that run from the upstream one of creating an object's conceptual design to a downstream one of creating an object's fully embodied design, with some intermediate stages between them. Most tellingly, van Aken and Berends employed the concept of business projects to transfer to the field of management a purposive theory of problem solving in engineering and architecture, according to which creating solutions consists in a multi-stage, cumulative activity, where each stage leading to an object and 
realization design involves a specific type of progression, demanding a specific frame of mind and intermediate goal. It is for this reason it's correct to say that van Aken and Berends offer a Simon-esque, design-oriented theorization of professional practice within organizations.

That's probably all you need to be told about van Aken and Berends' Problemsolving in Organizations, for the purposes of your visit to the Public Management Gallery. When you exit the exhibition, you can flip through a copy of the book, if you have time to visit the ground floor Gallery bookstore and café. If you have time for a tall coffee, grab hold of the book and work your way through Chapter 3. Don't forget to look at the handy diagrams.

Would you now please meet me at the next display.

\section{Listening to purposive theories of design-projects: Preparing for the Future}

The main title of the book featured here is Preparing for the Future: Strategic Planning in the U.S. Air Force, which was published by Brookings Institution Press. Given that this book is about strategic planning, you might wonder whether you've been surreptitiously tele-transported from the mezzanine to the upper floor, where the exhibits on works about public organizations are located. Don't worry; nothing of the sort has happened. Preparing for the Future could properly have been displayed there; but what I have to say about it targets the design-project layer of public management purposive theorizing.

If you haven't yet looked closely at the display, you might be expecting a presentation of the book's two authors, along with some fanfare. However, fanfare would be unseemly, as one of the co-authors of Preparing for the Future is yours truly. I am happy to introduce my co-author, Colin Campbell. When the book project began, back around 1998, Colin was a professor and director of Georgetown University's public policy school, in Washington, D.C. By the time we finished he was a professor of political science at University of British Columbia, from which he retired some years ago.

The book's topical focus was on mechanism-intent theorizing of public organizations. The term "strategic planning" was a reference to such theorizing. A question we considered was what strategic planning is for. In line with Fayol and Bryson, we took strategic planning as being for performance of a public organization's management function. We formulated a specific line of purposive theorizing about the role of the management function, a precedent for which was a line of argumentation in a popular management book, entitled Competing for the Future. ${ }^{17}$ We modified the argument, modestly, to cohere with purposive theorizing of public organizations.

The question of what strategic planning consisted in was pursued in an empirical, exploratory way, through reporting, analysis, and commentary on a raft of strategic planning cases that occurred within the U.S. Air Force (USAF) during a six-year period. One such case ran from mid-1995 through the end of 1996; one of its outcomes was an officially approved formulation of a USAF strategic vision, entitled Global Engagement. Another case ran from 1997 through 1999; 
one of the outcomes of this case of the U.S. Air Force Futures Games was a strategic planning directorate presentation to the Air Staff senior leadership on the insights, issues, and recommendations arising from the futures games. A third case was the source of a successor Air Force strategic vision, entitled Global Vigilance, Reach, and Power, completed in 2000. The book not only analyzed each case, but also compared them as part of an effort to add some depth to purposive theorizing about strategic planning as a mechanism to perform the management function in public organizations.

The case analysis and commentary established a few directions for my own theorizing of public management, which I have pursued since then. The direction I will pinpoint here is to theorize episodic strategic planning efforts, like the Air Force cases, as mechanisms to perform the management function in public organizations - and to theorize such mechanisms, in turn, as design-projects. To be honest, the process by which I pursued this direction of theorizing was through teaching, as these Air Force cases became staples of all of my courses. I think the first time I framed these cases as "strategic planning projects" was when I was teaching executive short courses for the Australia and New Zealand School of Government (ANZSOG), more than a decade ago. This direction of theorizing, involving a dialogue between "ideas" and "cases," continued, and it wasn't long before I was using van Aken and Berends' book as a theoretical reading to go alongside the Air Force cases. It's been that way ever since.

You'll remember from what I said about PSO that design-projects are usefully theorized as scenario-processes; this framing was pursued in analyzing the case studies of strategic planning in the USAF, both in the book and in case teaching. That is, the "cases" have been analyzed as design-project-type scenario-processes. This framing carries a number of conceptual implications, such as:

- Strategic planning efforts are episodes understood as projects;

- Strategic planning projects are mechanisms to perform a public organization's management function in specific respects;

- Strategic planning activities are constituted by sequences of professional activity on the part of many actors, participating on the basis of their role in the organization or some other identity within the situation at hand;

- A strategic planning project's final "object-designs" are commonly labeled as strategic plans;

- Initial conditions of strategic planning projects reflect how legacies of previous strategic planning projects relate to the way the launch of their successors is stage-managed;

- Dynamically-stable contexts of strategic planning projects include the organization's formal role system; the persona that top organizational leaders establish in relation to the specific strategic planning project; the way milestone and gateway reviews have been programmed; and the project's official narrative;

- Some of the constitutive activities of strategic planning projects have more in common with archetypes of designing, while other such activities have more in common with archetypes of decision-making; 
- How designing and decision-making come to be concatenated has substantial implications for the content and significance of the object-designs/ strategic plans that eventuate from strategic planning projects; and

- Presentational drawings of strategy content are intermediate outcomes of strategic planning projects; how top organizational leaders respond to them has a significant modifying effect on project's dynamically-stable context and, consequently, on strategic planning projects' outcomes and legacies.

Admittedly, this nine-fold set of bullet points is extensive and densely written. Relax, you will be allowed to leave the Gallery even if you can't recite them. What's really important is the impression that this material leaves, so, if you don't mind, let me suggest some impressions of this display, and the mezzanine floor as a whole, that you might want to take away with you.

First, purposive theorizing about public management is well served by focusing specifically on design-projects as a mechanism for performing enterprise functions in public organizations - not least, for performing the management function. (Caveat: don't be tricked into thinking that design-projects are exclusively constituted by design activity, when the concatenation between designand decision-making activity is key to how they work.)

Second, purposive theorizing of design-projects benefits from creative, critical thinking - and from analyzing empirical cases, for the same reasons why the same ingredients are beneficial for non-purposive, contemplative theorizing of phenomena as you encounter in social science research. Creative, critical thinking is a many-faceted process, but it does include formulating analogies among structures of ideas. As illustrated by the discussion of Preparing for the Future, fruitful analogies can be developed by seeing strategic planning and the creation of artificial systems as similar processes with qualitatively different outcomes. Likewise, you can see the benefit of analogies between design-projects and significant events in the unfolding history of a public organization.

Finally, I hope that you can see why purposive theorizing about public management needs to tap into two historical traditions of management as a professional discipline: the one represented by Moore (and also Bryson) and the one represented by Simon (and also van Aken and Berends). By this point in the Gallery Tour, you should be able to comprehend the attempt to blend these two traditions in forming the design-oriented professional discipline of public management.

If you will, now please make your way downstairs to the lower level of the Gallery, where you will be surrounded with theories about various forms of professional activity, all of which are crucial for public management as a professional practice, but none of which is unique to public management.

\section{Introducing theories of four professional activities}

Now that you've finished making your way downstairs, please take notice of the display welcoming you to the final portion of your tour of the Public Management Gallery. You saw the left-hand image as you entered the exhibit on 
the upper floor: it's here to remind you of the three-layer concept of purposive theorizing within the professional discipline of public management. If you look around, you'll also see some chairs; as this introduction to the lower floor of the Gallery will take a little time to present, you might want to relax your legs by sitting on one of them.

The aim of this part of the Gallery is to add depth to purposive theorizing of professional practice in public organizations. Accordingly, we must first ask what professional activities are for, and then turn to the question of what professional activities consist in. The idea of what professional activities are for is derived from the discussions of purposive theorizing of professional practice in public organizations that you heard while visiting the Gallery's upper and mezzanine floors. As such, there are two ways to present what they are for. One - keyed to the upper level - is that they are for performing enterprise functions of public organizations, including the management function. Another - keyed to the mezzanine - is that they are for effectuating design-projects. As for what professional activities consist in, the approach taken here is to see them as scenario-processes. As such, they consist in context-activity-outcome dynamics, just as Simon theorized design-projects. Professional activities should be theorized in a sufficiently granular way that professional practitioners in public organizations could easily recognize that they engage in them at work. In sum, professional activities are granular-scale scenario-processes whose context-activity-outcome dynamics effectuate design projects or otherwise contribute to performing a public organization's enterprise functions.

You might wonder why I didn't say that professional activities are compositional elements of the professional practice of public managers. After all, what unifies Mark Moore's theorization of public management is the idea of a public manager; and he theorizes this unifying idea by identifying a number of compositional elements, such as formulating a public organization's strategy, imagining how public value can be created, declaring a public organization's mission, engaging in political management, and managing trajectories in operational capacity. While that's all coherent in its own way, Moore's theorization is typically resisted by those who consider the idea of a public manager role as institutionally ill-fitting or culturally inappropriate. I wish for the purposive theory of professional practice in public organizations presented here to avoid this fate; and to that end, I have presented
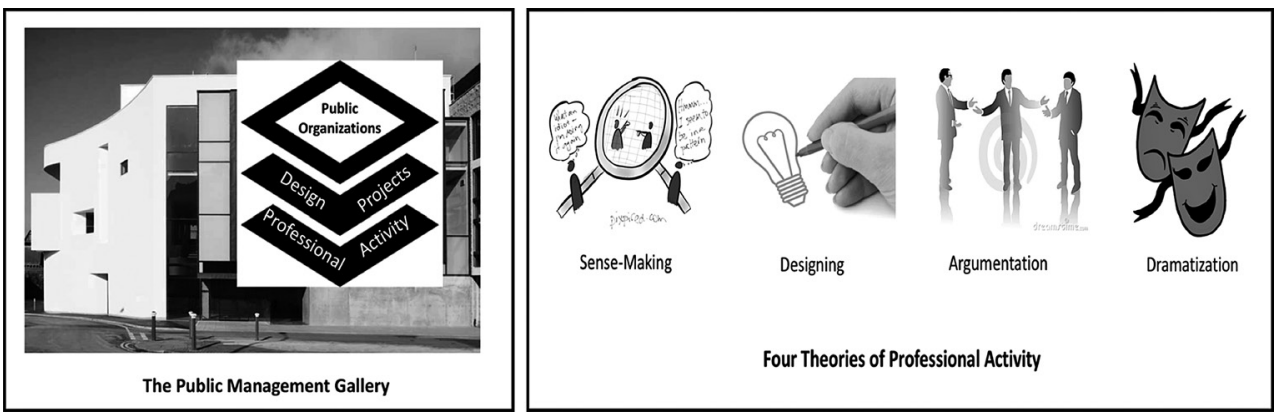

Figure 4.6 Entering the exhibition section on professional activities 
the idea of professional activities in ways that cohere and resonate with Herbert Simon's processual approach to theorizing professional practice, rather than in line with Moore's role-centered approach. Accordingly, as theorized here, professional practitioners in public organizations are designers and decision-makers; as such, they are problem-solvers. Being a problem-solver involves engagement across a spectrum of differentiated professional activities, every one of which involves lines of individual thinking and action, as well as episodes of interaction with others during unfolding events in local-present situations.

I've been using the plural term professional activities, without naming any specific variant of them. I think you can see why I did that, the main reason being that I decided to give absolute priority to preserving the Gallery's approach to purposive theorizing about professional practice in public organizations. An added reason is that any given list of variant forms of professional activity will displease pretty much everyone. I didn't want to make you feel that way, too soon. But I can't ask you to hang on any longer. So, here's the list:

- Sense-making in public organizations

- Designing in public organizations

- Argumentation in public organizations

- Dramatization in public organizations.

As you consider the list, please take into account what each and every one of these professional activities is for. The long-version is that they effectuate design-projects or otherwise contribute to performing a public organization's enterprise functions. We can also say that sense-making, designing, argumentation, and dramatization are for "problem-solving," in keeping the rhetoric of Simon's approach to theorizing professional practice. Having made this broad point, I'd like to suggest that problem-solving is effectuated by combinations of these professional activities. Put the other way around, these variant forms of professional activity contribute to problem-solving in distinct ways. Accordingly, the list should be evaluated as a totality, rather than item-by-item.

A reason for distinguishing designing from argumentation is that the literature on designing is separate from the literature on argumentation. Essentially, the literature on designing is about creating and representing purposeful phenomena for eventual realization and use, whereas the literature on argumentation is about thinking critically and communicating persuasively about issues to be resolved through individual or collective deliberation and choice. Making this delineation doesn't negate the fact that purposive theories of designing and argumentation share common roots, especially in the philosophy of Aristotle. ${ }^{18}$ It does, however, reflect academic specialization within universities, with designing being theorized mainly in architecture departments and engineering faculties, and with argumentation being theorized mainly in humanities faculties, in philosophy or rhetoric departments, mainly (though not exclusively). Reflecting this pattern of specialization, the literatures on designing and argumentation are written for different audiences. However, both are relevant for theorizing professional activity within public organizations. 
The background argument is Simon's theorization of problem-solving through design-projects, which held that problem-solving requires both (a) creating designs for purposeful phenomena and (b) making decisions, whether about the process of creating a purposeful phenomenon, or about the issue of whether to proceed to realize a design for one. It's obvious that the professional activity of designing is intrinsic to creating designs. Moreover, the idea that argumentation is intrinsic to decision-making in organizations is immediately apparent: that is how issues are tackled and how decisions are rationalized.

In theorizing sense-making, there's mileage to be gained in asking what it is for - and what it consists in. The professional activity of sense-making, like the two mentioned earlier, should be seen as being for problem-solving and, relatedly, for performing the enterprise functions of public organizations, including the management function. But sense-making can also be seen as an enabler of the professional activities of designing and argumentation. As an enabler, sense-making's role is to provide a starting point and ongoing context for these respective activities. To be enabling, sense-making must eventuate in a sense of situational orientation on the part of individual professional practitioners, as well as in some clarity about what ideas and observations are relevant to the professional activities of designing and argumentation, in the specific situation at hand. This way of theorizing sense-making is plainly built on the premise that neither designing nor argumentation can be done well without a sense of situational orientation and such clarity about relevance; and a further premise is that it takes - or should take - effort to establish these enabling conditions.

As for theorizing what sense-making consists in, one direction is to focus on cognitive process. Within this realm are many approaches and substantive theories. Some are more concerned with how individuals arrive at a situational understanding on the basis of direct experience, while others are more concerned with how individuals attend to, store, and retrieve information. In addition, the literature includes purposive theorizing of sense-making. Some of this literature is concerned with problem-solving generally, much as Herbert Simon was in much of his writing. Still, some purposive theorizing about sense-making is concerned with problem-solving in specific domains of professional practice. An example of sense-making practices in public management is stakeholder mapping, the outcome of which is insights on stakeholder power and interests. Thus, the literature that's pertinent to theorizing sense-making as a professional activity is extensive and varied, with some purposive theorizing being domain-independent (as in the literature on problem-solving), while other purposive theorizing is domainspecific, as in the case of stakeholder mapping and public management.

I'm now going to turn to the fourth item within the list of professional activities that make up professional practice in public organizations: dramatization. Dramatization might seem out of place here, for the reason that the other three ideas about professional activity clearly belong to the vocabulary of problemsolving. Nothing you've heard in listening to this audio-guide would have led you to anticipate coming across theories about dramaturgical activity. It's not that dramaturgical activity - for example, projecting character-roles and playingthrough performance routines - didn't appear in Moore's book, or Bryson's, or 
mine. Indeed, the case studies and illustrative examples of these books are clearly made of dramaturgical stuff. What is true is that dramaturgical activity was invisible, because, while it was part of the phenomenon of professional practice, dramaturgical activity was not theorized. The thesis here is that existing theories of dramatization - such as Goffman's - should become just as prevalent within purposive theorizing of professional activity as are theories of sense-making, designing, and argumentation.

I'll discuss dramatization in mechanism-intent terms, focusing entirely on what it consists in. In The Presentation of Self in Everyday Life, Goffman ${ }^{19}$ analogized social processes to staged dramatic performances, not just to such performances themselves, but also to what precedes them - such as scripting and to what is their result. Dramatic performances are scenario-processes involving events within "local-present" situations. Both the context and outcomes of dramatic performances are theorized, broadly, as social realities - a fundamental social theory concept. Social realities include a complex of social relations among those involved in the same local-present situation. The activity within dramatic performances consists in lines of action by individuals, as experienced by anyone who witnesses or participates actively in them. Such lines of action, in turn, are constituted by sequences of acoustical and gestural moves. Outcomes of dramatic performances are either validations or shifts in the social reality of a local-present situation, or some combination of the two.

This statement is plainly minimalist: it doesn't include any of the nuanced elaborations that made Goffman's theoretical discussion so profound and influential. For example, it doesn't mention steps taken to set the scene of dramatic performances, let alone those taken in scripting them. It doesn't mention the emergent properties of dramatic performances, arising from the interplay of individuals and their actions within local-present situations. However, nothing stands in the way of bringing this richer Goffmanian theoretical account of dramatic performances into purposive theorizing about professional activity within public organizations.

It's about time to get up from your chair to move to the main part of the lower-floor Gallery exhibition. If you're getting anxious to complete the Gallery Tour, don't worry. Testing of the audio-guide has shown that visitors are satisfied without hearing too much about the specifics of the featured literature on professional activities. They come away from what you will now hear with enough insight about the literature to read further on their own. So, please move into the main room. The fact that there's no chairs or benches should assure you that you won't be there for long.

\section{Exemplifying theories of professional activity}

Four books are on display in this gallery space, as you can quickly observe by scanning the scene.

The book about sense-making is Schemas in Problem-Solving, by Sandra P. Marshall (1995), now an emeritus professor of psychology at San Diego State University in California. Marshall's book was first published in 1995 by 


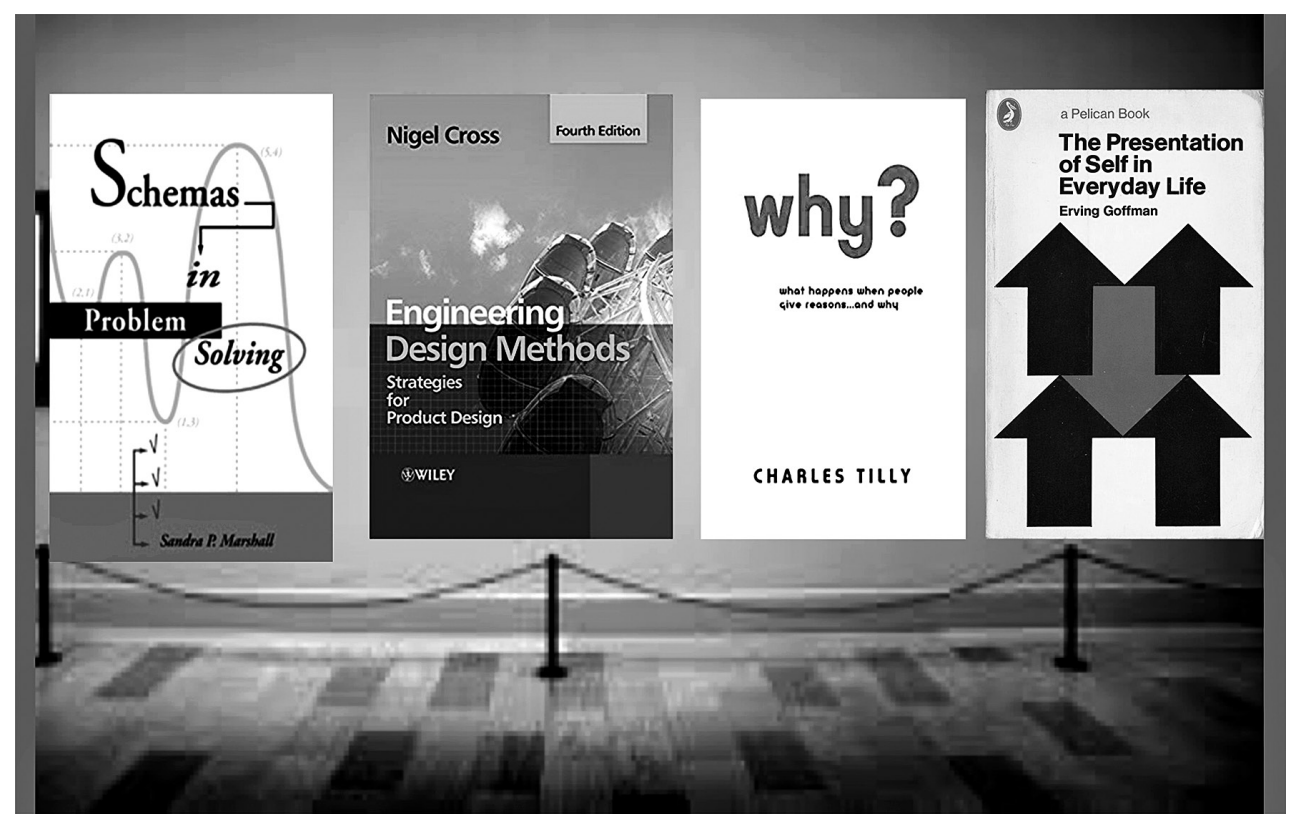

Sources:

Tilly, Charles, Why? [Cover]. @ 2006 Princeton University Press. (Book jacket image reprinted with permission.)

Cross, Nigel, Engineering Design Methods: Strategies for Product Design, Fourth edition. [Cover] @ 2008, John Wiley \& Sons. (Book jacket image reprinted with permission.)

Figure 4.7 Four theories of professional activity in public organizations (sense-making, designing, argumentation, and dramatization)

Cambridge University Press and has recently been updated and reissued. The book builds on decades of theorizing about human cognition to provide a theory of how problem-solving activity is channeled by conceptual schemas; and it also discusses how such schemas undergo change in response to experience and reflection on it.

Marshall introduces her book by explaining that the word and the concept it reflects date back to the writings of the ancient Greek philosophers, noting that schema is a letter-for-letter transliteration of $\sigma \chi \eta \mu \alpha$, which means form, shape, or figure. Marshall adds that, "almost every modern usage of schema draws upon a person's application of knowledge found in memory to make sense of some experience or event taking place in his or her world" (p. 8).

Marshall's theory of problem-solving includes four stages, which she refers to as functions, because they are intrinsic to how problem-solving works. The stages that relate to sense-making are identification and elaboration; the stages that relate to other aspects of problem-solving are planning and execution. In scenario-process terms, the outcome of identification is recognition of a situation, event, or experience, whereas the outcome of elaboration is understanding of what has come to be recognized. For identification, the schema/activity relation involves pattern recognition. This dynamic essentially involves assimilating a situation to one or more schema that have come to structure an individual's cognition. It is referred to as pattern recognition because schema consist in 
numerous linked elements and because no single condition within a situation, on its own, is the cause of the identification outcome. Once identification has been achieved, the elaboration stage kicks-off, with the situational frame resulting from the identification stage channeling the elaboration stage activity. Here, the schema used for identification helps an individual grasp how various conditions occurring or present in the situation are connected - constitutively, causally, or otherwise.

Marshall's book is evidently situated within the cognitive science literature. That categorization carries a few implications for purposive theorizing about sense-making. First, if you'd like to understand more about what schemas consist in - and how they function - the advice would be to read more within the cognitive science literature, specifically where schemas play a role. Some of that literature is written for a popular, educated audience, with noteworthy examples being Lakoff and Johnson's Metaphors We Live By, ${ }^{20}$ Cialdini's Pre-suasion, ${ }^{21}$ and Konnikova's Mastermind: How to Think Like Sherlock Holmes. ${ }^{22}$ Some of the relevant cognitive science literature is written for a broad academic audience, with noteworthy examples being Murphy's The Big Book of Concepts ${ }^{23}$ and Fauconnier and Turner's The Way We Think. ${ }^{24}$ Second, you might want to read about sensemaking from perspectives different from cognitive science. An exceptionally prominent source is Karl Weick, whose writings on sense-making began with his Social Psychology of Organizing. ${ }^{25}$

The book about designing is Engineering Design Methods, by Nigel Cross, ${ }^{26}$ now an emeritus professor of design studies at The Open University in Britain and a seminal figure in the field of design studies in Europe and beyond. This book builds on more than a century of theorizing about product design, picking up on some classic German theorizing from the late nineteenth century. That said, the first chapter's inspiring and closely-reasoned discussion of problem-solving is not confined to the book topic. For this reason, it's well-suited to theorizing designing, when this scenario-process is understood as a professional activity that is for effectuating design projects and for problem-solving more generally.

Cross' first chapter includes a compact and clear discussion of the widely-held idea that, when a design-project begins, the problem to be solved is ill-defined. Clients don't know how to communicate what they want to the designers, if they even know what they want. At this early stage, designers don't know what constraints pose design restrictions or trade-offs. Cross adds to this picture of design-projects an element that is reminiscent of the idea of garbage-can decision-making, namely, that the situation within the design-project includes ideas about what the object or product should be. These ideas have come into the situation because some designer or the client has an inclination to push for them; whether these ideas are suitable as design solutions is another matter entirely. Cross' theory of the professional activity of designing acknowledges that design-projects have something in common with the organized anarchies of the garbage-can model of organizational choice: namely, solutions chase problems. This complication then sets the scene for the rest of Cross' purposive theorizing of designing.

The hallmark of the ensuing argument is that designing consists in two co- 
occurring scenario-processes, both involving the same people in the designer and client roles. The two scenario-processes are problem-structuring and solution-structuring. Oversimplifying, the outcome of problem-structuring is definitive client intent as it relates to the design-project, whereas solution-structuring eventuates in definitive designs for the object or product. The details of this argument are instructive - and should not be missed by anyone interested in critical, generative thinking about designing as a professional activity, no less in public organizations than elsewhere.

The book about argumentation is Why? What Happens when People Give Reasons, and Why, by Charles Tilly, ${ }^{27}$ who passed away several years ago after a distinguished academic career in sociology, teaching mainly at the University of Michigan and Columbia University. As the title suggests, Tilly's book is not a work of professional philosophy. It examines argumentation - the giving of reasons - as a social process. Under Tilly's analysis, giving reasons is part-and-parcel of defining a person's social relations with others. While that reality pervades situations and events where reason-giving occurs, it's also the case that reason-giving takes different forms, depending on the specifics of the situation and event concerned. In filling out this theory, Tilly proposes a four-fold classification of forms of reason-giving: convention, coded arguments, technical arguments, and stories. Arguments about performing enterprise functions and effectuating design-projects, in particular, can be seen as combinations of coded and technical arguments as well as stories. They're all relevant to professional activity in public organizations.

Tilly's book is quite well-suited to being a point of departure in learning about the literature on argumentation for a few reasons. First, it's written from the standpoint of argumentation being for problem-solving, which is evident in the use of examples. Second, it sees argumentation as consisting in how people represent their thinking to others, which provides a way to theorize what argumentation consists in. Along these lines, the idea that argumentation consists in four distinct forms - convention, codes, technical arguments, and stories - provides some depth to the idea. The analysis and thoughtful commentary in the book would surely help a professional practitioner think generatively and critically about how to engage in argumentation as a professional activity within public organizations.

All that said, there's plenty of other works to read on argumentation. In public administration, you shouldn't miss Hood and Jackson's Administrative Argument. ${ }^{28}$ In public policy, you should look into Majone's Evidence, Argument and Persuasion in the Policy Process ${ }^{29}$ and Dunn's Public Policy Analysis. ${ }^{30}$ Some of the literature on how to do academic writing is relevant. A good example is Booth, Colomb, and Williams, The Craft of Research. ${ }^{31}$ And, of course, the philosophical literature on argumentation is as relevant as it is endless.

We conclude with Goffman's Presentation of Self in Everyday Life, the obvious choice for a purposive theory of dramatization, as was discussed while you were seated in the ante-room of this floor's exhibit. There isn't much more to say to recommend it, other than to mention its stratospheric Google citation count. Just go buy it in the Gallery bookstore. You can find it to the left of the Gallery Tour logo, mounted on the wall ahead. 
Figure 4.8 Logo of the Public Management Gallery

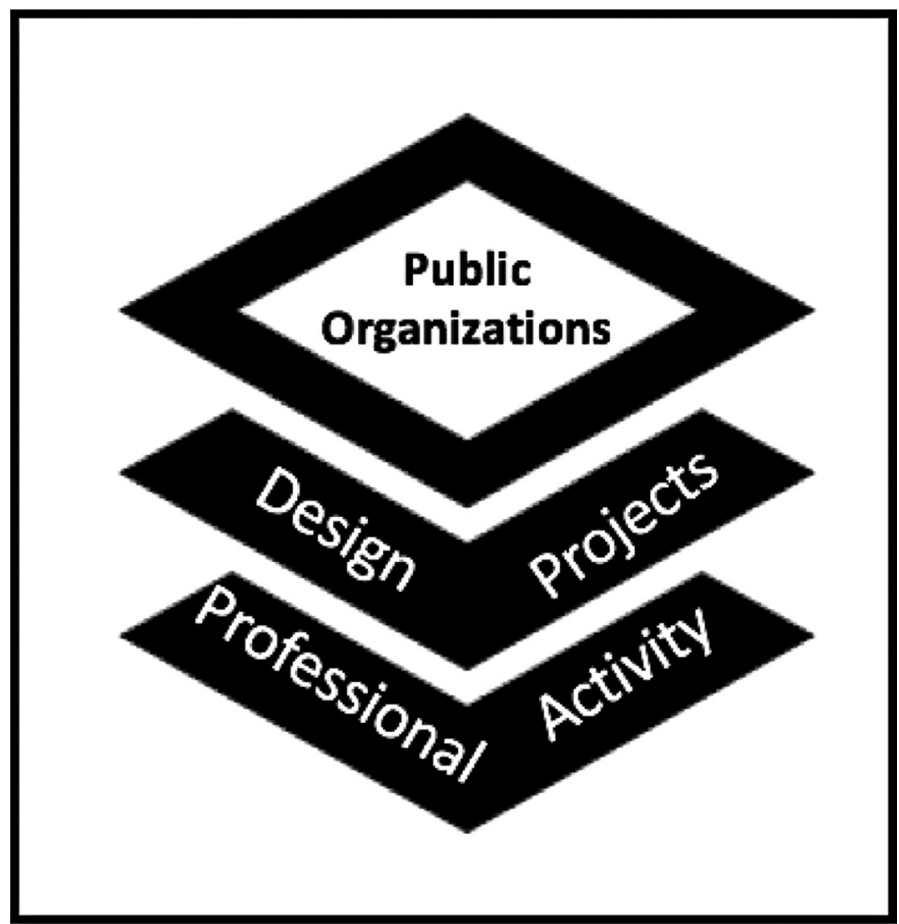

This concludes the audio-guide presentation of the Public Management Gallery Tour. I trust that you've enjoyed your visit. I hope you'll return for a refresher in the weeks, months, and years ahead.

\section{NOTES}

1 For information about the Bauhaus Archive, view https://www.bauhaus.de/en/das_bauhaus/44_idee/ (Accessed April 26, 2019). For a history, see Droste (2011).

2 Moore (1995).

3 Porter's second major text - Porter (1985) - is more relevant than the first in this respect.

4 Rumelt, Schendel, and Teece (1994).

5 Fayol (1919/1984).

6 Ariew and Perlman (2002); Leroi (2014).

7 Mintzberg (1983).

8 Barnard (1938/1968), Guillén (1994), Williamson (1995).

9 Simon (1947/1968), March and Simon (1958), Perrow (1986).

$10 \operatorname{Simon}(1996)$.

11 Augier and March (2011).

12 Van Aken and Berends (2018).

13 The main one was van Aken (2004). I discuss it in Barzelay (2012).

14 Lasswell (1971).

15 Hirschman $(1973,1991)$.

16 Lindblom (1959, 1990).

17 Hamel and Prahalad (1995).

18 Ariew and Perlman (2002).

19 Goffman (1959).

20 Lakoff and Johnson (1980).

21 Cialdini (2016). 
22 Konnikova (2013).

23 Murphy (2002).

24 Fauconnier and Turner (2002).

25 Weick (1979).

26 Cross (2008).

27 Tilly (2006).

28 Hood and Jackson (1991).

29 Majone (1989).

30 Dunn (2015).

31 Booth, Colomb, and Williams (2008). 